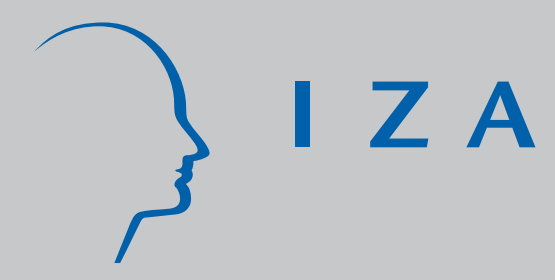

IZADP No. 2710

Unemployment and Gang Crime:

Could Prosperity Backfire?

Panu Poutvaara

Mikael Priks

March 2007 


\title{
Unemployment and Gang Crime: Could Prosperity Backfire?
}

\author{
Panu Poutvaara \\ University of Helsinki \\ and IZA \\ Mikael Priks \\ University of Munich

\section{Discussion Paper No. 2710 \\ March 2007} \\ IZA \\ P.O. Box 7240 \\ 53072 Bonn \\ Germany \\ Phone: +49-228-3894-0 \\ Fax: +49-228-3894-180 \\ E-mail: iza@iza.org
}

\begin{abstract}
Any opinions expressed here are those of the author(s) and not those of the institute. Research disseminated by IZA may include views on policy, but the institute itself takes no institutional policy positions.

The Institute for the Study of Labor (IZA) in Bonn is a local and virtual international research center and a place of communication between science, politics and business. IZA is an independent nonprofit company supported by Deutsche Post World Net. The center is associated with the University of Bonn and offers a stimulating research environment through its research networks, research support, and visitors and doctoral programs. IZA engages in (i) original and internationally competitive research in all fields of labor economics, (ii) development of policy concepts, and (iii) dissemination of research results and concepts to the interested public.
\end{abstract}

IZA Discussion Papers often represent preliminary work and are circulated to encourage discussion. Citation of such a paper should account for its provisional character. A revised version may be available directly from the author. 
IZA Discussion Paper No. 2710

March 2007

\section{ABSTRACT \\ Unemployment and Gang Crime: Could Prosperity Backfire?}

Empirical evidence reveals that unemployment tends to increase property crime but that it has no effect on violent crime. To explain these facts, we examine a model of criminal gangs and suggest that there is a substitution effect between property crime and violent crime at work. In the model, non-monetary valuation of gang membership is private knowledge. Thus the leaders face a trade-off between less crime per member in large gangs and more crime per member in small gangs. Unemployment increases the relative attractiveness of large and less violent gangs engaging more in property crime.

JEL Classification: K42, D71, D74

Keywords: violence, crime, gangs, unemployment, identity

Corresponding author:

Panu Poutvaara

Department of Economics

University of Helsinki

P.O. Box 17 (Arkadiankatu 7)

FIN-00014 Helsinki

Finland

E-mail: panu.poutvaara@helsinki.fi

\footnotetext{
*We wish to thank Larry Blume for helpful comments.
} 


\section{Introduction}

Gang crime is a serious and common phenomenon. Based on survey results, the US Department of Justice estimates that more than 24500 gangs and 772500 members were active in 3300 jurisdictions across the United States in 2000 (OJJDP Fact Sheet, 2002). In Los Angeles, for example, 720 gangs consisting of 39000 members have been identified. These gangs are responsible for a majority of the murders in the city (Los Angeles Times, February 6, 2007). Moreover, according to a survey of 212 US schools made in 2006 by the "National Gang Crime Research Center", 25 percent of American schools reported a gang shooting near their school during the last year (Knox 2006).

In richer countries, such as the United States, Italy or France, criminal gangs are often concentrated to relatively poor areas. Organized crime has even more severely infected countries with widespread poverty, heavy corruption and history of violent internal conflicts, like Russia, Serbia and Montenegro, and several other former Soviet or Yugoslav Republics. These observations have suggested that tackling unemployment problem should automatically reduce crime, by improving the outside options of potential perpetrators.

However, empirical evidence has not established such general connection. In an extensive analysis of 63 studies, Chiricos (1987) finds that unemployment has a statistically significant positive effect on property crime in 40 percent of the studies, while the effect on violence is statistically significant and positive in only 22 percent of the cases. More recently, Raphael and Winter-Ebmer (2001), Agell and Nilsson (2003) and Fougère et al. (2006) find a strong positive link between unemployment and property crime but a small or no link between unemployment and violent crime for the US, Sweden and France, respectively. Levitt (2004, p. 170), summarizing a number of empirical papers, writes that "almost all of these studies report a statistically significant but substantively small relationship between unemployment rates and property crime...Violent crime, however, does not vary systematically with the unemployment rate."

In this paper we offer a theory of street gangs, which can help to explain the ambiguity between unemployment and crime.

To reflect the empirical evidence of the gang structure, we model gangs to consist 
of leaders and ordinary members. Following Padilla (1992), utility from belonging to a gang consists of social identity, prestige, protection and respect on the streets, and benefits from networking with the like-minded. Members differ in their valuation of these benefits, which is their private knowledge. In return, members have to commit violent crime, such as extortion or gang violence with the purpose to obtain drug turfs, or property crime, like pickpocketing or auto theft. Leaders benefit from crime committed by members. In addition, leaders reap benefits from the total number of members in terms of prestige, and can, in line with empirical evidence (Padilla 1992 and Levitt and Venkatesh 2000), decide whom to admit as members. Because there are adverse labor market consequences of gang membership (Hagedorn 1988 and Padilla 1992), our model assumes that gang members cannot find jobs in the legal labor market.

Members who value membership more can always mimic those with lower valuation. As a consequence of this, leaders face a trade-off. One alternative is to select a highlydemanding norm that results in a small group with a high level of crime per member, either in terms of severe property crime or violent crime. The cost is that the leader has fewer followers to give him prestige. The other alternative is to go for a lessdemanding norm where members are, for example, required to steal cars, leading to a larger group. Our analysis reveals that a reduction in unemployment may encourage leaders to either marginally moderate their demands, or to radically change to smaller gangs with more severe crime. Because more unemployment reduces relatively more the amount of crime that leaders can require from the type valuing identity less, leaders may shift focus from property crime to violent crime at the cost of losing the members valuing membership least. This helps to explain the empirical observations that, in aggregate, unemployment tends to increase property crime but not violent crime.

The economic literature on organized crime was pioneered by Buchanan (1973), Neher (1978), Reuter (1983), Schelling (1984) and later Fiorentini and Pelzman (1995). Buchanan (1973) and Neher (1978) analyze the effect of the number of criminal organizations. Akerlof and Yellen (1994) analyze the relationship between police enforcement against gangs and community co-operation. Levitt and Venkatesh (2000) study empirically the financial activities of a drug-selling street gang. Konrad and Skaperdas (1997) analyze how gangs' ability to commit affects violence and Skaperdas (2001) 
studies other determinants of organized crime.

In an intriguing recent contribution, Mansour et al. (2006) model the formation of gang structure as endogenous. They find that deterrence can have the effect of breaking up drug cartels formed by criminal organizations, which leads to larger output and lower prices. Like Mansour et al. (2006), we also identify a case in which a change that could be ex ante expected to have an unambiguously positive impact, in our case reduction in unemployment, may backfire by increasing criminality. However, in our framework backfiring may happen without a change in the number of gangs.

The rest of the paper is organized as follows. The model and basic results are presented in Section 2. In Section 3, we show how unemployment affects crime. Section 4 concludes.

\section{The Model}

A gang consists of leaders and members. Members may join a gang in order to obtain "identity", as is most evident in case of ethnic gangs, or to benefit from protection that the gang provides to its members (see e.g. Padilla 1992 and Anderson 1999). In exchange for providing membership benefits, leaders can, but need not, require members to commit crimes. There are two types of crime: property crime and violent crime. By violent crime, we denote more severe crime like robberies, extortion, or gang violence with the purpose to obtain drug turfs. There is a discontinuity in the amount of violent crime one can commit: it has to be either zero or reach a minimum level, denoted by $\underline{c}^{v}$. Property crime, on the other hand, can take any non-negative values. These assumptions are motivated by the empirical facts that violent crimes, even in their milder forms, in most countries are punished harshly by the society. Property crime, however, may start from modest shoplifting, which may lead to low costs if caught, and range up to stealing cars or burglary.

Leaders derive monetary utility from crimes that members are required to commit on their behalf, and from the total number of members. There are two types of members, 1 and 2, differing in their valuation of gang membership. We denote variables 
referring to type $j, j \in\{1,2\}$ by subscript $j .{ }^{1}$ The number of potential members of type $j$ is $n_{j}$, and the number of members of type $j$ who stay and are not expelled is $m_{j}$, giving as total membership $m=m_{1}+m_{2}$. The number of leaders is normalized to unity.

At the first stage, leaders declare a minimum level of crimes $\left(\widehat{c}^{p}, \widehat{c}^{v}\right)$ required from members. At the second stage, members decide how much crimes to commit. After observing the crimes committed by individual members, leaders decide whether to keep them or expel them.

Leaders cannot distinguish an individual member's private valuation of membership. This is a reasonable assumption, as members who value identity highly have an incentive to lie about their type. Leaders therefore must establish a norm asking for one level of crimes only.

Committing property crimes of level $c^{p}$ generates a cost $\lambda^{p} c^{p} . \quad \lambda^{p}$ is a marginal cost parameter capturing sanctions by the justice system, as well as possible social and psychological costs. Committing violent crimes of level $c^{v}$ generates a cost $\lambda^{v} c^{v}$. $\lambda^{v}$ is a marginal cost parameter capturing sanctions by the justice system, social and psychological costs, as well as the risk of injuries and physical or psychological suffering associated with criminal activities. Members of type $j$ receive benefits $\alpha_{j}$ from membership, so that $\alpha_{2}>\alpha_{1}$. Total utility for a member of type $j$ who chooses a level of property (violent) crimes $c_{j}^{p}\left(c_{j}^{v}\right)$ and is not expelled is

$$
u_{j}=\alpha_{j}-\lambda^{p} c_{j}^{p}-\lambda^{v} c_{j}^{v}
$$

while the utility of the expelled members is outside option $w$. Outside option $w$ may reflect, among other things, labor market prospects of tentative members. As membership in a gang may easily stigmatize, it is assumed that outside option is available only for those who do not belong to a gang. ${ }^{2}$

\footnotetext{
${ }^{1}$ Our results would generalize into more than 2 discrete groups.

${ }^{2}$ While we model the outside option as uniform for all members, the results could be easily generalized to a case in which there are several groups of members, each with its own outside option. In that case, leaders could price discriminate between potential members belonging to population groups with varying levels of outside option. What drives the result is that the difference between the valuation of gang membership and the outside option is private knowledge. If we would assume that valuation is common knowledge, then all results would go through assuming that the outside option is private knowledge, and there are two possible levels. Our framework could also be extended to include both
} 
Aggregate levels of crimes that members commit are therefore

$$
\begin{aligned}
& C^{p}=m_{1} c_{1}^{p}+m_{2} c_{2}^{p} \\
& C^{v}=m_{1} c_{1}^{v}+m_{2} c_{2}^{v} .
\end{aligned}
$$

Leaders receive utility

$$
u_{l}=\pi m+\beta^{p} C^{p}+\beta^{v} C^{v} .
$$

By $\pi>0, \beta^{p}>0, \beta^{v}>0$, leaders receive a positive utility from the aggregate level of property and violent crimes by their gang members, and from the number of members who stay. One reason why leaders have a reason to care about the number of members, even if members do not, is that leaders are evaluated according to how many followers they have. We call the utility that leaders derive from the number of followers prestige.

Leaders may expel those who commit less crimes than they require, in which case the expelled lose membership benefits and receive payoff of outside option $w$. Leaders announce a minimum level of criminality required, characterized by $\left(\widehat{c}^{p}, \widehat{c}^{v}\right)$, and then expel the members who do not fulfill it. Expulsion following defection is necessary to maintain credibility. Crimes are committed and membership benefits are received as a flow. For both types of members, the participation constraint is that the expected utility from membership must be higher than the outside option, implying that requirement

$$
\alpha_{j}-\lambda^{p} c_{j}^{p}-\lambda^{v} c_{j}^{v} \geq w
$$

needs to be satisfied for type $j$ to stay. Notice that whether violent crime is profitable for leaders depends on how the difference between the returns to different types of crime to leaders relates to the difference between the costs of different types of crime to members. Without loss of generality, we assume that if indifferent between violent crime and property crime, leaders choose property crime. We find:

Lemma 1 Requiring a positive level of violent crime can be profitable only if

$$
\beta^{v}>\frac{\lambda^{v}}{\lambda^{p}} \beta^{p}
$$

being private knowledge, in which case there would be several discrete groups. 
and

$$
\alpha_{2} \geq w+\lambda^{v} \underline{c}^{v}
$$

Proof. See Appendix.

Lemma 1 provides a necessary but not a sufficient condition for a gang leader to require violent crime. The condition is not sufficient as it does not compare yet payoffs from alternative strategies. For example, requiring only property crime may be optimal to keep members with lower valuation on board. We next establish that leaders do at least as well by focusing on only one type of crime than by asking a positive level of both property and gang crime:

Lemma 2 Focusing on only property or violent crime gives at least as high a utility than requiring a strictly positive level of both.

Proof. See Appendix.

Leaders face two alternative strategies. One is to choose such level of crimes that both types stay, and another to choose such a level that only type 2 stays. When pursuing either strategy, leaders have to decide whether to ask for property crime or violent crime. Note that as there is a minimum value of violent crime that is feasible, it may be that the strategy of requiring violent crime is not feasible. The condition that has to be satisfied for requiring violent crime from type 1 is

Condition 1. Leaders can require violent crime from type-1 members if and only if

$$
w \leq \alpha_{1}-\lambda^{v} \underline{c}^{v}
$$

Correspondingly, it holds for type 2 that

Condition 2. Leaders can require violent crime from type-2 members if and only if

$$
w \leq \alpha_{2}-\lambda^{v} \underline{c}^{v}
$$


Provided Condition 1 is satisfied, leaders can choose a strategy of requiring a level of violence with which type-1 members are indifferent between staying and leaving. This is given by

$$
\widehat{c}_{1}^{v}=\frac{\alpha_{1}-w}{\lambda^{v}} .
$$

Provided that Condition 2 is satisfied, leaders can choose a strategy of requiring a level of violence with which type- 2 members are indifferent between staying and leaving. This is given by

$$
\widehat{c}_{2}^{v}=\frac{\alpha_{2}-w}{\lambda^{v}}
$$

Note that as $\alpha_{2}>\alpha_{1}$, Condition 2 implies that Condition 1 is also satisfied. The reverse need not hold. The other two strategies are choosing a requirement of property crime so that either both types or only type- 2 stays. If leaders want to ensure both types to stay with property crime, they choose

$$
\widehat{c}_{1}^{p}=\frac{\alpha_{1}-w}{\lambda^{p}}
$$

for the $\left(n_{1}+n_{2}\right)$ members that stay. If leaders are willing to sacrifice type 1 members to extract more property crime from type 2 , they choose

$$
\widehat{c}_{2}^{p}=\frac{\alpha_{2}-w}{\lambda^{p}}
$$

for the $n_{2}$ staying members.

We can now solve for the optimal strategies by leaders:

Proposition 1 (i) If (4) or Condition 2 is not satisfied, leaders choose $\widehat{c}_{1}^{p}$ if

$$
n_{1} \pi \geq \beta^{p}\left(n_{2} \widehat{c}_{2}^{p}-\left(n_{1}+n_{2}\right) \widehat{c}_{1}^{p}\right)
$$

and $\widehat{c}_{2}^{p}$ otherwise. (ii) If (4) and Condition 1 are satisfied, leaders choose $\widehat{c}_{1}^{v}$ if

$$
n_{1} \pi \geq \beta^{v}\left(n_{1} \widehat{c}_{2}^{v}-\left(n_{1}+n_{2}\right) \widehat{c}_{1}^{v}\right)
$$


and $\widehat{c}_{2}^{v}$ otherwise. (iii) If (4) and Condition 2 are satisfied but Condition 1 is not satisfied, leaders choose $\widehat{c}_{1}^{p}$ if

$$
n_{1} \pi \geq \beta^{v} n_{2} \widehat{c}_{2}^{v}-\beta^{p}\left(n_{1}+n_{2}\right) \widehat{c}_{1}^{p}
$$

and $\widehat{c}_{2}^{v}$ otherwise.

Proof. See Appendix.

Note that in each regime that is listed in Proposition 1, leaders face a choice between a smaller gang with more crime per member, and a large and less demanding gang. The proposition has several implications:

First of all, prestige that leaders derive from the number of members may, but need not, encourage leaders to reduce their requirement of crime. ${ }^{3}$ For example, because of prestige considerations, leaders may opt for a larger gang that pursues property crime, instead of a small one specializing in violent crime, as evident from case (iii).

Second, toughening the punishment for violent crime or reducing the punishment for property crime may encourage gang leaders initially pursuing violent crime to switch to property crime. To see this, notice that leaders may find it optimal to pursue violent crime only if (4) is satisfied, and that $\lambda^{p}\left(\lambda^{v}\right)$ includes marginal cost of property (violent) crime for members.

Also, changing the payoffs of different types of crime to leaders has corresponding effects. For example, reducing profits that leaders derive from property crime (that is, reducing $\beta^{p}$ ) may result in a backlash in violence if leaders change strategies to smaller and more violent gangs.

\section{$3 \quad$ Unemployment and Crime}

Taking into account that unemployment is usually only temporary and that a career as a member of criminal gang may exclude employment in the legal market, it is natural to interpret the outside option $w$ to reflect the expected income available from the

\footnotetext{
${ }^{3}$ Note that leaders may choose a larger gang even if they would not derive utility from prestige. To see this, notice that if $n_{2} / n_{1}$ would approach to zero, the right-hand sides of (9), (10) and (11) would each be negative. Then, a larger group would be optimal even without prestige.
} 
legal labor market. With a given level of wages, a reduced unemployment improves the outside option $w$ that the members face. One could expect this to be unequivocally beneficial when targeting crime. However, notice that when the valuation of gang membership is private knowledge, leaders suffer from mimicking constraint if they want to keep also members of type 1 . As members of type 2 can claim to be of type 1, keeping type 1 members restricts the level of crime that can be extracted from type 2 , also. Increasing the outside option $w$ reduces relatively more crime that can be required from type 1 members, rendering keeping them relatively more expensive in terms of forgone crime. This intuition can be summarized as two propositions:

Proposition 2 If membership does not change, a decrease in unemployment results in a marginal reduction in crime, whether the gang specializes in violent or property crime.

Proof. By Proposition 1, leaders choose (5), (6), (7) or (8). The claim follows as each of these is decreasing in $w$, corresponding to a decrease in unemployment.

Proposition 3 An decrease in unemployment may trigger a change from a larger gang with less crime to a smaller gang with more crime, including a possible shift from a gang specializing in property crime to a smaller gang specializing in violent crime.

Proof. When the right-hand side of (9), (10) or (11) is negative, it is never optimal to choose such a strategy that leads to a smaller gang. When the right-hand side is positive, whether leaders go for a smaller gang with more low-intensity crime or a larger gang with more high-intensity crime depends on their relative valuation of different types of crime and prestige from membership. As the right-hand sides are then decreasing in $w$, a decrease in unemployment may trigger a switch to the smaller gang with more crime.

Propositions 2 and 3 have empirically testable implications. Proposition 2 implies that if reduced unemployment is not associated with a change in the size of gangs, then total amount of crime that leaders receive should decrease. Proposition 3 implies that if a small reduction in unemployment would lead into a change in gang membership, this would be a switch to a more hard-line gang, either with a discrete increase in the level of property or violent crime, or a switch from property to violent crime. 
Together, Propositions 2 and 3 provide an economic interpretation for why empirical studies find that while unemployment tends to increase property crime, the effect on violent crime is not clear. If gangs become smaller when unemployment is reduced, then they may also become more violent. In this case, leaders replace property crime by violent crime. However, if the size of gangs does not change, then both property and violent crime are reduced when unemployment goes down.

\section{Concluding Remarks}

This paper suggests an explanation to the empirical regularity whereby unemployment tends to increase property crime, but not violent crime. We focus on gangs and suggest that there is a substitution effect between property crime and violent crime at work. Gang members differ in their valuation of gang membership and this is their private knowledge, while the outside option of gang members reflects observable labor market situation, and is negatively linked to unemployment. Members with high valuation can always mimic those with lower valuation. Thus, gang leaders have to choose a common norm of crime to all members who are identical in their observable characteristics, including the outside option. A reduction in unemployment makes the mimicking effect more severe. The reason is that reduced unemployment improves the outside option for both the members with low valuation of gang membership and those with high valuation. The improved outside option reduces the willingness to pay for gang membership for both types, the reduction being relatively larger for members with a lower valuation. As a result, it may be optimal for leaders to forgo membership benefits from those with low valuation of membership, and establish a higher level of requirement that only those with high valuation are willing to satisfy. Hence, a reduction in unemployment may cause a move towards smaller and more violent gangs, thus increasing violent crime.

Our results should not be interpreted as an advice not to reduce unemployment, in fear of this boosting gang violence. Instead, they highlight the need to properly study violent gangs, in order to anticipate whether such problems are likely to arise. Social policies that reduce unemployment may backfire by resulting in smaller and more criminal gangs. As a result, policing and social policies may, under certain circumstances, 
be complements rather than substitutes. In order to cancel the backfiring effect, reduced unemployment may actually call for more rather than less policing in previously troubled neighborhoods.

Our finding is connected to the insight by Mansour et al. (2006) who find that a tougher crime deterrence may increase the number of gangs. In their model, policing targets more efficiently large gangs. The potential for backfiring results when tougher policing causes large cartels to break into smaller gangs that cannot coordinate to restricting the amount of drugs sold to the level that would maximize the profits of a monopoly cartel. However, we find that the backfiring effect need not require that the number of gangs changes, or that the gangs would coordinate on the amount of criminal activity.

Our results also imply a need for an integrated judicial policy: too tough penalties for property crime may backfire by resulting in more violent crime. Similarly, reducing the prestige that leaders derive from membership may backfire by hardening their stance. In addition to gang crime, such a mechanism may help to explain the radicalization of ideological, ethnic or religious groups under certain circumstances.

We presented our analysis using a simple model in which the marginal benefit of the two types of crime to leaders is constant. The analysis could be straightforwardly generalized to allow for several types of crimes, each with its own payoffs and costs. By varying the costs of different crimes, society can choose which crimes it suffers. Furthermore, changes in unemployment and other forms of outside option affect the trade-offs available.

\section{References}

[1] Agell Jonas and Nilsson Anna (2003), "Crime, Unemployment and Labor Market Programs in Turbulent Times", forthcoming in the Journal of the European Economic Association.

[2] Akerlof Georg A. and Kranton Rachel E. (2000), "Economics and Identity", Quarterly Journal of Economics, 115: 715-753.

[3] Anderson Elijaha (1999), Code of the Street (Norton, New York). 
[4] Buchanan James M. (1973), "A Defence of Organized Crime", in The Economics of Crime and Punishment, Rottemberg S (ed.) (Washington, D.C., The American Enterprise Institute, 1973).

[5] Chiricos Theodor (1987), "Rates of Crime and Unemployment: An Analysis of Aggregate Research Evidence", Social Problems, 34:187-211.

[6] Hagedorn John (1988), People and Folks: Gangs, Crime and the Underclass in a Rustbelt City (Chicago: Lake View Press).

[7] Fiorentini Gianluca and Peltzman Sam (1995), The Economics of Organized Crime, (Cambridge University Press, Cambridge).

[8] Fougère Denis, Francis Kramarz and Julien Pouget (2006), "Youth Unemployment and Crime in France", IZA Discussion Paper No. 2009.

[9] Konrad Kai and Skaperdas Stergios (1997), "Credible Threats in Extortion", Journal of Economic Behavior and Organization, 33: 23-39.

[10] Knox George W. (2006), "Findings from the K-12 Survey Project, a Special Report of the NGCRC", Mimeo, The National Gang Crime Research Center.

[11] Levitt Steven D. and Venkatesh Sudhir (2000), "An Economic Analysis of a DrugSelling Gang's Finances", Quarterly Journal of Economics, 115: 755-789.

[12] Levitt Steven D. (2004), "Understanding Why Crime Fell in the 1990s: Four Factors that Explain the Decline and Six that Do Not", Journal of Economic Perspectives, 18: 163-190.

[13] Los Angeles Times (February 6, 2007) "Los Angeles Names and Targets City's Worst 11 Gangs"

[14] Mansour Abdala, Marceau Nicolas and Mongrain Steeve (2006), "Gangs and Crime Deterrence", Journal of Law, Economics and Organization, 22: 315-339.

[15] Neher Philip A. (1978), "The Pure Theory of the Muggery", American Economic Review, 68: 437-45. 
[16] OJJDP Fact Sheet (2002), "Highlights of the 2000 National Youth Gang Survey", Mimeo, US Department of Justice, Office of Juvenile Justice and Delinquency Prevention,

[17] Padilla Felix M. (1992), The Gang as an American Enterprise (Rutgers University Press, New Jersey).

[18] Raphael Steven and Winter-Ebmer Rudolf (2001), "Identifying the Effect of Unemployment on Crime", Journal of Law \& Economics, 44: 259-284.

[19] Reuter Dennis (1983), Disorganized Crime, Illegal Markets and the Mafia (MIT Press, Cambridge)

[20] Schelling Thomas (1984), "What is the Business of Organized Crime?" in Choice and Consequence, (Harvard university press, Cambridge).

[21] Skaperdas Stergios (2001), "The Political Economy of Organized Crime: Providing Protection when the State Does Not", Economics of Governance, 2: 173-202.

\section{APPENDIX}

Proof of Lemma 1. (1) Let us first analyze an arbitrary positive level $\widetilde{c}^{v}$ of violent crime, in case $\underline{c}^{v}=0$. The utility cost is for a gang member $\lambda^{v} \widetilde{c}^{v}$. A corresponding utility cost would arise from increasing the amount of property crime by $\widetilde{c}^{v} \lambda^{v} / \lambda^{p}$. The utility that the gang leader would receive from violent crime $\widetilde{c}^{v}$ is $\beta^{v} \widetilde{c}^{v}$. The utility from replacing this by property crime would be $\beta^{p} \widetilde{c}^{v} \lambda^{v} / \lambda^{p}$. The utility from property crime exceeds that from violent crime if $\beta^{v}<\frac{\lambda^{v}}{\lambda^{p}} \beta^{p}$, and they are equal if $\beta^{v}=\frac{\lambda^{v}}{\lambda^{p}} \beta^{p}$. Remembering the assumption that in case of indifference gang leader requires property crime, a necessary condition for it being profitable to require any positive amount of violent crime is that $\beta^{v}>\frac{\lambda^{v}}{\lambda^{p}} \beta^{p}$. 2) When $\underline{c}^{v}>0$, one has also to take into account the participation constraint of potential members. A necessary condition for it being optimal to require violent crime is that at least members who value membership most (i.e., members of type 2) are willing to stay at least if no property crime is required in addition to $\underline{c}^{v}$, giving as condition $\alpha_{2}-\lambda^{v} \underline{c}^{v} \geq w$.

Proof of Lemma 2. Make a counterassumption that the gang leaders would require a strictly positive level of both types of crime. A necessary condition for this 
is that $\alpha_{2} \geq w+\lambda^{v} \underline{c}^{v}$. Otherwise, requiring a positive level of violent crime cannot be optimal as there would be no members. Assume next that this holds. If $\beta^{v}<\frac{\lambda^{v}}{\lambda^{p}} \beta^{p}$, then requiring a positive level of violent crime cannot be optimal by Lemma 1 . On the other hand, if $\beta^{v}>\frac{\lambda^{v}}{\lambda^{p}} \beta^{p}$ then it would be optimal to stop requiring property crime and increase the requirement of violent crime so that the total burden on members does not change. This leaves the case in which $\beta^{v}=\frac{\lambda^{v}}{\lambda^{p}} \beta^{p}$. In this case, leaders would receive the same utility by dropping the requirement of violent crime and replacing this by increasing the requirement by property crime so that the utility of members does not change. This completes the proof that leaders never strictly prefer requiring a positive level of both types of crime.

Proof of Proposition 1. We first show that it is never optimal for leaders to choose any other level of crime than those specified in equations (5) to (8). If leaders would choose a level above either (6) and (8), no members would stay and thus reducing the level of crime to either of these levels would improve leaders' utility. If leaders would require a level of violence (property crime) below (6) ((8)) but above (5) $((7))$, then leaders could increase the requirement to the level $(6)((8))$ without causing any members to leave. Correspondingly, if leaders would require a level of violence (property crime) below $(5)((7))$, then leaders could increase the requirement to this level without causing any members to leave. (i) If (4) is not satisfied, it is not profitable for leaders to require violence. If Condition 2 is not satisfied, leaders cannot require violence as they would then lose all members. In either case, the choice between leaders is for utility in case of choosing (7) or (8). (ii) By (4) and Condition 1, leaders prefer to require violence and can choose as the level of violence (5) or (6). The maximization problems simplifies to choosing between these two. (iii) By (4) and Condition 2 but not Condition 1 being satisfied, leaders prefer to require violence if only members of type 2 stay, while they have to restrict to requiring property crime if also members of type 1 stay. 